\title{
EMERGÊNCIA E QUALIDADE DE MUDAS DE Enterolobium contortisiliquum (Vell.) Morong (Fabaceae) EM DIFERENTES SUBSTRATOS ${ }^{1}$
}

Fabricio Gomes Gonçalves², Rodrigo Sobreira Alexandre², Aderlan Gomes da Silva ${ }^{3}$, Eliane de Queiroz Lemes $^{4}$, Andreice Patrícia da Rocha ${ }^{5}$ e Mikaely Pereira de Arruda Ribeiro ${ }^{6}$

\begin{abstract}
RESUMO - Este trabalho objetivou avaliar diferentes substratos na emergência e crescimento de mudas de Enterolobium contortisiliquum. Foram avaliadas composições a partir dos materiais vermiculita, moinha de carvão vegetal, subsolo, composto orgânico e serragem de madeira, totalizando 16 tratamentos. Durante 120 dias, avaliaram-se a emergência, o índice de velocidade e o tempo médio de emergência, a altura total da planta, o comprimento da raiz, o comprimento da parte aérea, o diâmetro do colo, o número de nódulos, a massa seca da raiz, a massa seca da parte aérea e o volume de raiz, além do índice de qualidade de Dickson. A maioria dos substratos apresentou resultados satisfatórios, destacando-se os tratamentos com $50 \%$ de vermiculita e $50 \%$ de composto orgânico e o tratamento com 33\% de vermiculita, 33\% de moinha de carvão vegetal e 33\% de composto orgânico.
\end{abstract}

Palavras-chave: Produção de mudas; Recuperação de áreas degradadas; Leguminosa.

\section{EMERGENCY AND QUALITY OF Enterolobium contortisiliquum (Vell.) Morong (Fabaceae) SEEDLINGS IN DIFFERENT SUBSTRATES}

\begin{abstract}
The present study aimed to evaluate the influence of different materials in the emergency and growth of Enterolobium contortisiliquum seedlings. Distinct substrates were formulated using vermiculite, charcoal wastes, subsoil, organic compost and wood sawdust, consisting of 16 treatments. The variables emergency, speed index and average time of emergency, total height of the plant, length of the root, length of the stem, root collar diameter, number of nodules, root and stem dry mass, root volume, and the Dickson Quality Index, were analyzed during 120 days. Almost all the substrates provided satisfactory results, especially the treatments with $50 \%$ of vermiculite, $50 \%$ of organic compost and the treatment with $33 \%$ vermiculite, $33 \%$ charcoal wastes and $33 \%$ organic compost.
\end{abstract}

Keywords: Seedlings production; Recovering of degraded areas; Legume specie.

\section{INTRODUÇÃO}

Entre os fatores que influenciam a produção de mudas de espécies florestais, destacam-se, além da semente, o recipiente e o substrato utilizados, os quais vão refletir diretamente na qualidade da muda (SANTOS et al., 2000).
Enterolobium contortisiliquum (Vell.) Morong, comumente conhecida como orelha-de-macaco, orelhade-negro, orelha-de-onça, tamboril e timbaúva, pertence à família Fabaceae Mimosoideae. É uma árvore de grande porte e crescimento rápido, encontrada em diversas formações florestais brasileiras, mais frequentemente

\footnotetext{
${ }^{1}$ Recebido em 17.10.2012 aceito para publicação em 23.10.2013.

${ }^{2}$ Departamento de Ciências Florestais e da Madeira, Universidade Federal do Espírito Santo, UFES, Brasil. E-mail: $<$ fabricio.goncalves@ufes.br>e < rodrigosobreiraalexandre@gmail.com>.

${ }^{3}$ Instituto Federal de Educação, Ciência e Tecnologia de Minas Gerais - IFMG, Campus de São João Evangelista, MG, Brasil. E-mail: <aderlan.silva@ifmg.edu.br>.

${ }^{4}$ Mestre em Produção Vegetal, Universidade Federal do Espírito Santo, UFES, Brasil. E-mail: <elaqueiroz@yahoo.com.br>.

${ }^{5}$ Centro Educacional Ferreira Nunes - CECON, Divinópolis, MG, Brasil. E-mail: <andreicepatricia@gmail.com>.

${ }^{6}$ Centro de Treinamento Missionário Vida, Blumenau, SC, Brasil. E-mail: <mik_arruda@hotmail.com>.
} 
colonizando áreas desmatadas, em clareiras e bordas de matas (SCALON et al., 2005).

As plantas leguminosas, em razão da grande diversidade de espécies, versatilidade de usos potenciais e de seu papel na dinâmica dos ecossistemas, têm sido muito indicadas na recuperação de áreas degradadas. Isso ocorre devido à sua associação simbiótica que fixa o nitrogênio do ar, ou ao mutualismo com fungos micorrízicos, propiciando maior aproveitamento do fósforo e de outros nutrientes no solo (FRANCO et al., 1992) ou, ainda, ao rápido crescimento e elevada produção de biomassa.

A formação de mudas florestais de boa qualidade envolve os processos de germinação de sementes, iniciação e formação do sistema radicular e da parte aérea, que estão diretamente relacionados com características que definem o nível de eficiência dos substratos. Para isso, os substratos devem apresentar algumas características desejáveis, entre elas oferecer boa estrutura e consistência, de forma a sustentar as sementes ou estacas durante a germinação ou enraizamento e ser suficientemente poroso, permitindo a drenagem do excesso de água para que se mantenha adequada aeração do sistema radicular (GONÇALVES et al., 2000). Além disso, devem apresentar boa capacidade de retenção de água para que se evite estresse hídrico, diminuindo a necessidade constante de irrigação (CARNEIRO, 1995).

Cunha et al. (2005) também afirmaram que maior ênfase tem sido dada à pesquisa de diferentes combinações de substratos, que claramente influenciam o vigor, o crescimento e a sanidade das mudas produzidas. Entre os diversos materiais utilizados como substratos, é muito comum a recomendação de misturas a partir da utilização de subsolo, areia, serragem de madeira ou de casca de pinus e adubos químicos, podendo-se alterar a proporção desses materiais até certo limite.

Gonçalves et al. (2000) acrescentaram que o substrato deve estar prontamente disponível em quantidades adequadas e a custos economicamente viáveis. Cunha et al. (2005) mencionaram que os resíduos orgânicos surgem como alternativa para diminuir os custos com adubação química. Nesse sentido, o objetivo deste trabalho foi avaliar a emergência, crescimento e qualidade de plântulas e mudas de E. contortisiliquum em diferentes composições de substratos.

\section{MATERIAL E MÉTODOS}

O estudo foi conduzido na casa de vegetação do Instituto Federal de Educação, Ciência e Tecnologia de Minas Gerais - Campus São João Evangelista, localizado no Município de São João Evangelista, MG,

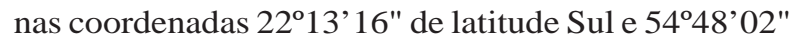
de longitude Oeste e altitude média de $452 \mathrm{~m}$. O clima é classificado como Cwa - inverno seco e verão chuvoso (KÖPPEN, 1948), com temperatura média máxima anual de $26,1^{\circ} \mathrm{C}$ e média mínima anual de $15^{\circ} \mathrm{C}$. O índice médio pluviométrico anual é de $1.081 \mathrm{~mm}$. O estudo foi realizado entre os meses de julho a dezembro.

Foram coletados no campus frutos de $E$. contortisiliquum de cinco árvores-matriz, produtivas e sadias, com altura e diâmetro à altura do peito médios de 18 m e 1,2 m, respectivamente. Os frutos apresentavamse sem orifícios visíveis a olho nu que propiciassem a entrada de patógenos. Depois de extraídas dos frutos e antes de serem colocadas para germinar, as sementes sofreram um tratamento pré-germinativo de escarificação com lixa d'água n ${ }^{\circ} 10$ e imersão em água destilada por 12 h, conforme Alexandre et al. (2009), para homogeneizar a germinação.

No experimento foram utilizados 16 tratamentos compostos, basicamente, de cinco materiais e suas misturas [vermiculita (VE), subsolo (TB), composto orgânico (CO), serragem de madeira (SM) e moinha de carvão (MC)], a saber: T1 = VE (33\%) + MC (33\%) + TB (33\%); T2 = VE (33\%) + MC (33\%) + CO (33\%); $\mathrm{T} 3=\mathrm{VE}(33 \%)+\mathrm{MC}(33 \%)+\mathrm{SM}(33 \%) ; \mathrm{T} 4=\mathrm{MC}(33 \%)$ + TB (33\%) + CO (33\%); T5 = MC (33\%) + TB (33\%) + SM (33\%); T6 = TB (33\%) + CO (33\%) + SM (33\%); $\mathrm{T} 7=\mathrm{VE}(50 \%)+\mathrm{MC}(50 \%) ; \mathrm{T} 8=\mathrm{VE}(50 \%)+\mathrm{TB}(50 \%) ;$ $\mathrm{T} 9=\mathrm{VE}(50 \%)+\mathrm{CO}(50 \%) ; \mathrm{T} 10=\mathrm{VE}(50 \%)+\mathrm{SM}(50 \%) ;$ $\mathrm{T} 11=\mathrm{MC}(50 \%)+\mathrm{TB}(50 \%) ; \mathrm{T} 12=\mathrm{MC}(50 \%)+\mathrm{CO}$ (50\%); T13 = MC (50\%) + SM (50\%); T14 = TB (50\%) + CO (50\%); T15 = TB (50\%) + SM (50\%); е T16 = CO $(50 \%)+$ SM (50\%).

Os cinco materiais e os 16 tratamentos foram encaminhados para o Laboratório de Análises de Solo do IFMG - Campus São João Evangelista, para caracterização química.

Como características, foram analisados o Índice de Velocidade de Emergência (IVE) (MAGUIRRE, 1962), Emergência (E\%), Tempo médio de emergência, em dias (TME) (LABORIAU, 1983), Altura total da planta (AT), do ápice da raiz ao ápice da parte superior da muda, 
Comprimento da raiz (CR), do colo até o ápice da raiz, Comprimento da parte aérea (CPA), a partir do colo até o ápice da muda, Diâmetro do colo (DC), Número de nódulos (NOD), Massa seca da raiz (MSR), Massa seca da parte aérea (MSPA) e Volume de raiz (VR).

Para análise do IVE (1), E\% e TME (2), foram realizadas contagens diárias de até 15 dias após a instalação do experimento, para averiguar o número de plântulas emergidas, aqui consideradas aquelas plântulas que sobressaíam do substrato.

$$
I V E=\frac{\sum_{i=1}^{n} P_{i}}{D_{i}}
$$

em que IVE = índice de velocidade de emergência, $\mathrm{P}_{\mathrm{i}}$ = número de plântulas emergidas no i-ésimo dia de contagem e $\mathrm{D}_{\mathrm{i}}=$ número de dias em que as plântulas levaram para emergir no i-ésimo dia de contagem

$$
T M E=\frac{\sum_{i=1}^{n} n_{i} t_{i}}{n_{i}}
$$

em que TME = tempo médio de emergência, em dias; $\mathrm{n}_{\mathrm{i}}=$ número de plântulas emergidas no intervalo entre cada amostragem; e $t_{i}=$ tempo médio decorrido entre o início da emergência e a i-ésima contagem

Os dados de porcentagem de emergência e o número de nódulos foram transformados em $\operatorname{arcosen} \sqrt{x / 100}$ e submetidos à análise estatística, sendo o “ $\mathrm{x}$ ” $\mathrm{a}$ porcentagem de emergência das plântulas e o número de nódulos presente nas raízes, de forma independente.

Foram semeadas duas sementes por saquinho, permitindo, dessa forma, uma repicagem após o período de emergência de 15 dias. Os saquinhos foram dispostos em uma caixa plástica de 50 × 30 x 10 cm (20 saquinhos em cada caixa), em uma bancada suspensa a $90 \mathrm{~cm}$ de altura do solo, no interior da casa de vegetação, melhorando a ergonomia durante as medições. A altura das mudas, o diâmetro do colo, o volume de raízes e a massa das mudas foram avaliados aos 30, 60, 90 e 120 dias após o replantio, realizado após o período final de emergência e de forma que fosse padronizado um exemplar em cada recipiente (saquinho). Para permitir que o replantio fosse possibilitado, cinco saquinhos a mais para cada tratamento foram providenciados, visando à existência de mudas sobressalentes.
Os nódulos formados nos substratos foram quantificados, não sendo determinada a presença de bactérias fixadoras de nitrogênio. Com base nos dados, foi calculado o Índice de Qualidade de Dickson (IQD) (3), segundo Dickson et al. (1960 citados por GOMES et al., 2002), após cada período estipulado.

$$
I Q D=\frac{M S T}{\left[\left(\frac{H}{D C}\right)+\left(\frac{M S P A}{M S R}\right)\right]}
$$

em que MST = massa seca total, $\mathrm{H}=$ altura da parte aérea, DC = diâmetro de colo da muda, MSPA = massa seca da parte aérea e MSR = massa seca da raiz.

Todas as características de vigor avaliadas foram transformadas em uma área sob a curva (ASC) (4) em função do tempo, de acordo com Campbell e Madden (1990), para possibilitar a avaliação integral de todo o período do experimento. As análises estatísticas foram realizadas após a transformação dos dados (equação 4).

$$
A S C=\sum_{i}^{n-1}\left(\frac{y_{i}+y_{i+1}}{2}\right) *\left(t_{i+1}-t_{i}\right)
$$

em que $\mathrm{y}_{\mathrm{i}}$ e $\mathrm{y}_{\mathrm{i}+1}=$ estimativa do ponto central do parâmetro avaliado; e $\mathrm{t}_{\mathrm{i}}$ e $_{\mathrm{i}+1}=$ tempo de duração do evento avaliado.

Utilizou-se o delineamento experimental em blocos casualizados, sendo cinco blocos (repetições) constituídos por 16 tratamentos e 25 repetições cada. Nos 16 tratamentos foram realizadas análises de variância (ANOVA). As médias foram avaliadas através do teste de Tukey sempre que o teste $\mathrm{F}$ apresentasse significância a $5 \%$.

\section{RESULTADOS}

Na Tabela 1, encontra-se o resultado da análise dos substratos e dos tratamentos. O resumo da análise de variância da emergência, do índice de velocidade, do tempo médio de emergência e do índice de qualidade de Dickson para E. contortisiliquun nos tratamentos avaliados está apresentado na Tabela 2.

Na análise estatística (Tabela 2), o IVE e o IQD apresentaram diferença significativa a 5\% de confiança. O substrato que apresentou melhor IVE, portanto de maior vigor, foi o tratamento 6 (TB 33\% + CO 33\% + SM 33\%) (Figura 1).

Revista Árvore, Viçosa-MG, v.37, n.6, p.1125-1133, 2013 
Tabela 1 - Resultado da análise química dos tratamentos e substratos utilizados.

Table 1 - Result of the chemical analysis of the treatments and substrates.

\begin{tabular}{|c|c|c|c|c|c|c|c|c|c|c|c|}
\hline \multirow[b]{2}{*}{ Tratamento } & \multicolumn{11}{|c|}{ Variáveis } \\
\hline & $\begin{array}{c}\mathrm{pH} \\
\left(\mathrm{H}_{2} \mathrm{O}\right)\end{array}$ & $\begin{array}{c}\mathrm{P} \\
(\mathrm{mg} / \mathrm{dm})\end{array}$ & $\begin{array}{c}\mathrm{K} \\
(\mathrm{mg} / \mathrm{dm})\end{array}$ & $\begin{array}{l}\mathrm{Ca}^{+2} \\
(\%)\end{array}$ & $\begin{array}{c}\mathrm{Mg}^{+2} \\
\text { (dag/kg) }\end{array}$ & $\begin{array}{c}\mathrm{Al}^{+3} \\
(\mathrm{mg} . / \mathrm{L})\end{array}$ & $\begin{array}{c}\mathrm{H}+\mathrm{Al} \\
\left(\mathrm{cmol}_{\mathrm{c}} / \mathrm{dm}^{3}\right.\end{array}$ & $\begin{array}{c}\text { CTC } \\
\text { ') } \mathrm{cmol}_{\mathrm{c}^{\prime}}\end{array}$ & $\begin{array}{c}V \\
\left.n^{3}\right)(\%)\end{array}$ & $\begin{array}{c}\mathrm{MO} \\
\text { (dag/kg) }\end{array}$ & $\begin{array}{l}\text { P-rem } \\
\text { (mg/L) }\end{array}$ \\
\hline 1 & 5,70 & 24,0 & 221 & 3,20 & 2,00 & 0,25 & 4,52 & 10,29 & 56,1 & 1,33 & 40,0 \\
\hline 2 & 5,84 & 25,3 & 159 & 10,4 & 5,25 & 0,20 & 3,24 & 19,30 & 83,2 & 7,92 & 46,4 \\
\hline 3 & 5,28 & 58,3 & 267 & 2,25 & 1,70 & 0,60 & 4,37 & 9,00 & 51,4 & 10,40 & 62,0 \\
\hline 4 & 5,46 & 28,3 & 149 & 9,05 & 1,95 & 0,15 & 5,05 & 16,43 & 69,3 & 7,84 & 32,4 \\
\hline 5 & 5,95 & 24,8 & 152 & 3,15 & 1,50 & 0,15 & 3,35 & 8,39 & 60,1 & 9,75 & 25,2 \\
\hline 6 & 5,52 & 35,3 & 205 & 8,65 & 2,40 & 0,15 & 4,04 & 15,61 & 74,1 & 13,04 & 28,1 \\
\hline 7 & 5,90 & 49,2 & 370 & 4,45 & 4,20 & 0,45 & 5,46 & 15,06 & 63,7 & 2,41 & 56,4 \\
\hline 8 & 5,86 & 10,5 & 159 & 2,30 & 4,30 & 0,10 & 4,52 & 11,53 & 60,8 & 0,09 & 30,3 \\
\hline 9 & 5,32 & 31,4 & 755 & 15,45 & 1,75 & 0,05 & 4,88 & 24,01 & 79,7 & 1,32 & 6,1 \\
\hline 10 & 4,80 & 32,3 & 544 & 2,20 & 1,85 & 0,25 & 2,90 & 8,34 & 65,2 & 16,31 & 41,4 \\
\hline 11 & 5,80 & 7,7 & 834 & 4,35 & 0,50 & 0,70 & 5,77 & 12,75 & 54,7 & 23,40 & 69,1 \\
\hline 12 & 5,54 & 43,9 & 1383 & 15,45 & 0,75 & 0,35 & 5,28 & 25,02 & 78,9 & 2,61 & 21,0 \\
\hline 13 & 5,23 & 94,7 & 1073 & 2,75 & 0,80 & 0,60 & 5,58 & 11,87 & 53,0 & 3,47 & 28,5 \\
\hline 14 & 6,16 & 163,9 & 1383 & 12,15 & 0,60 & 0,10 & 3,06 & 19,35 & 84,2 & 3,14 & 7,9 \\
\hline 15 & 6,30 & 6,3 & 360 & 3,25 & 0,40 & 0,05 & 2,10 & 6,67 & 68,5 & 3,99 & 19,5 \\
\hline 16 & 5,38 & 332,6 & 1383 & 12,95 & 1,45 & 0,35 & 4,13 & 22,07 & 81,3 & 5,34 & 11,0 \\
\hline VE & 6,42 & 44,8 & 827 & 6,75 & 2,60 & 0,35 & 2,43 & 13,90 & 82,5 & 7,95 & 1,4 \\
\hline MC & 5,62 & 55,6 & 1246 & 1,95 & 0,35 & 0,60 & 6,97 & 12,46 & 44,1 & 3,79 & 18,4 \\
\hline TB & 5,92 & 0,60 & 66 & 1,35 & 0,85 & 0 & 9,51 & 11,88 & 19,9 & 9,30 & 48,1 \\
\hline $\mathrm{CO}$ & 5,90 & 180 & 1419 & 21,3 & 1,7 & 0,25 & 3,95 & 30,58 & 87,1 & 13,84 & 57,4 \\
\hline SM & 4,36 & 35,3 & 438 & 1,45 & 0,7 & 1,20 & 4,32 & 7,59 & 43,1 & 3,36 & 18,4 \\
\hline
\end{tabular}

Tabela 2 - Resumo da análise de variância e erro-padrão residual $\left(\mathrm{S}_{\mathrm{xy}}\right)$ para emergência (E\%), índice de velocidade de emergência (IVE), tempo médio de emergência (TME) em dias e índice de qualidade de Dickson (IQD).

Table 2 - Summary of the variance analysis and residual standard error (Sxy) for emergency (E\%), speed index of emergency (IVE), average time of emergency (TME) in days and Dickson Quality Index (IQD).

\begin{tabular}{|c|c|c|c|c|c|}
\hline \multirow{2}{*}{ Fonte de variação } & \multirow{2}{*}{ GL } & \multicolumn{4}{|c|}{ Quadrado médio do resíduo } \\
\hline & & E (\%) & IVE & TME & IQD \\
\hline Tratamentos & 15 & $0,0060213^{\mathrm{ns}}$ & $2,544^{*}$ & $0,348^{\mathrm{ns}}$ & $87,56 *$ \\
\hline Resíduo & 64 & 0,00595 & 1,237 & 0,217 & 25,904 \\
\hline $\mathrm{S}_{\mathrm{xy}}$ & - & 0,00867 & 0,135 & 0,056 & 7,168 \\
\hline
\end{tabular}

* significativo a 5\%, pelo teste F; e ${ }^{\text {ns }}$ não significativo.

O comprimento de raiz (CR), o comprimento de parte aérea (CPA), a altura total (AT), a massa seca da parte aérea (MSPA) e a massa seca da raiz (MSR) (Figuras 2 e $3 \mathrm{AB}$, respectivamente) apresentaram diferença significativa nos tratamentos, sendo o tratamento 9 (50\% de VE e $50 \%$ de CO) o melhor, porém o tratamento 2 (33\% de VE e 33\% de CO + 33\% MC) também apresentou bons resultados para todos os parâmetros apresentados anteriormente.

\section{DISCUSSÃO}

O tratamento 15 (50\% subsolo e 50\% de serragem de madeira) apresentou baixo nível de fósforo. Todos os valores das variáveis analisadas, com exceção do $\mathrm{H}+\mathrm{Al}$, apresentaram-se sensivelmente mais elevados nos substratos que receberam o composto orgânico, em comparação com o subsolo, indicando elevação da fertilidade desse substrato, graças ao aumento dos teores de P, K, Ca, Mg e, ainda, da CTC.

Revista Árvore, Viçosa-MG, v.37, n.6, p.1125-1133, 2013 
Percebe-se que alguns tratamentos apresentaram maior nível de certos nutrientes, sendo, portanto, mais férteis. Por exemplo, o tratamento 14 apresentou melhores níveis de $\mathrm{pH}, \mathrm{P}, \mathrm{Ca}$ e $\mathrm{K}$, muito importantes para o crescimento das plantas. Neste trabalho, apenas o tratamento 10, composto pela mistura de VE (50\%) + SM (50\%), apresentou $\mathrm{pH}$ 4,8 fora da faixa que, segundo Abreu et al. (2012), é recomendada para a maioria das cul-turas $(5,0$ a 6,5$)$.

A análise química dos tratamentos permite inferir que há grande disponibilidade de nutrientes, sobretudo nas fases iniciais de crescimento, em especial do fósforo. Segundo Grant et al. (2001), as limitações na disponibilidade de $\mathrm{P}$ no início do ciclo vegetativo podem resultar em restrições no crescimento, das quais a planta não se recupera posteriormente, mesmo aumentando o suprimento de $\mathrm{P}$ a níveis adequados. O suprimento adequado de $\mathrm{P}$ é, pois, essencial desde os estádios iniciais de crescimento da planta. A presença de subsolo nos tratamentos 11 (moinha de carvão) e 15 (serragem de madeira) apresentou baixíssimos teores de P. Constata-se que quase todos os nutrientes essenciais ao crescimento das plantas estão com bons resultados, exceto o Ca no tratamento 10 com vermiculita e serragem de madeira.

De acordo com Barreto e Ferreira (2011), a emergência de E. contortisiliquum é epígea-fanerocotiledonar. As sementes deste trabalho foram submetidas à escarificação em lixa d’água $n^{\circ} 10$ e imersão em água destilada por $12 \mathrm{~h}$, conforme Alexandre et al. (2009), para homogeneizar a emergência das plântulas. Malavasi e Malavasi (2004) já recomendaram a escarificação mecânica pelo uso de lixa d’água para a superação de dormência de sementes da espécie E. contortisiliquum. O mesmo também foi recomendado por Braga et al. (2009) para Enterolobium schomburgkii, só que neste caso a lixa d'água foi a de $n^{\circ}$ 80. Ramos e Andrade (2010) recomendaram lixa de madeira como tratamento para a superação da dormência física de sementes de $E$. glaziovii. Em outros trabalhos, esses autores recomendaram o uso da escarificação química com ácido sulfúrico por 10 min (SCALON et al., 2006) e 1 h (LIMA et al., 2007).

A emergência não diferiu entre os tratamentos estudados (Tabela 2). Havendo, porém, pequenos comportamentos diferenciados no desenvolvimento das mudas, conforme visualizado na Figura 1. Nos tratamentos com serragem de madeira, a alta drenagem reduziu a disponibilidade de água necessária, comprometendo a porcentagem de emergência. Enquanto nos tratamentos em que o subsolo foi misturado com vermiculita ou serragem de madeira, a emergência de plântulas foi maior. Isso se deve a um substrato mais poroso, porém com maior capacidade de retenção de umidade, o que fez que não houvesse perda de água rapidamente. Araújo e Sobrinho (2011) verificaram que a emergência e o IVE tiveram melhor desempenho nos substratos solo + esterco bovino curtido e solo + palha de arroz carbonizada. De igual forma, Iossi et al. (2003) observaram que as plântulas de Phoenix roebelenii tinham menor crescimento quando se usavam os substratos areia, vermiculita e serragem de madeira. Afonso et al. (2012), avaliando o efeito de substrato comercial na produção de E. contortisiliquum, também afirmaram que a associação da areia proporcionou maior expressão do vigor das sementes e maior crescimento das mudas.

Segundo Nakagawa (1999), quanto maior a velocidade de emergência das plântulas, menor o tempo de exposição das sementes a fatores adversos do ambiente, os quais podem causar deterioração e até mesmo prejuízo, em termos produtivos. Assim, quanto maior o IVE, maior a velocidade de emergência, o que permite inferir que mais vigoroso é o lote de sementes

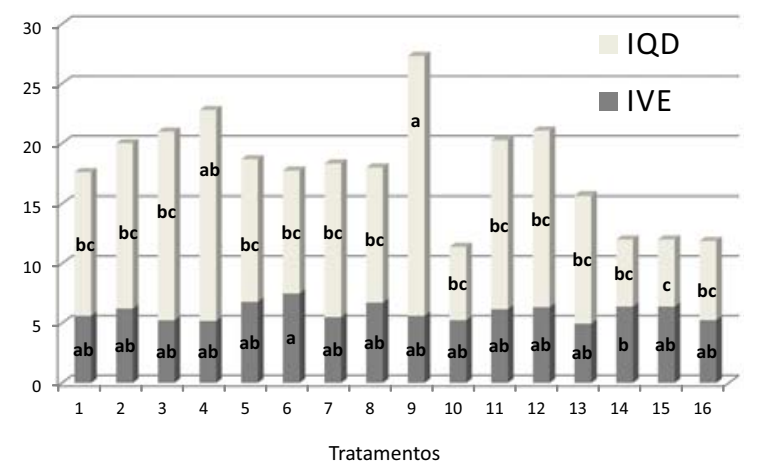

Figura 1 - Índice de velocidade de emergência (IVE), em dias, e índice de qualidade de Dickson (IQD), de plântulas e mudas de E. contortisiliquum, provenientes de diferentes substratos. Médias seguidas pela mesma letra não diferem estatisticamente entre si, pelo teste de Tukey a 5\% de significância.

Figure 1 - Speed index of emergency (IVE), in days and Dickson Quality Index (IQD) of E. contortisiliquum, plantules and seedlings, from different substrates. Means followed by the same letter do not differ statistically, according to the Tukey test (5\% significance).

Revista Árvore, Viçosa-MG, v.37, n.6, p.1125-1133, 2013 
avaliado. Para o IQD (Figura 1), o tratamento 9 (VE $50 \%$ + CO 50\%) proporcionou maior qualidade da muda. Higashikawa et al. (2010) detectaram baixa densidade no substrato vermiculita e, de acordo com Abad et al. (2001), a densidade perfeita de substratos deve ser menor que $400 \mathrm{~kg} \mathrm{~m}^{-3}$, o que resulta no favorecimento do crescimento radicular.

Segundo Fonseca et al. (2002), as características morfológicas e as relações utilizadas para avaliação da qualidade de mudas não devem ser utilizadas isoladamente para a classificação do padrão da qualidade de mudas, a fim de que não corra o risco de selecionar mudas altas, porém fracas, descartando as menores, mas com maior vigor.

A análise de variância realizada $(\mathrm{F}>0,05)$ indicou que o diâmetro do colo (DC) não variou significativamente entre os diferentes substratos, apresentando, em média, $0,45 \mathrm{~cm}$ e crescimento linear que atingiu, ao final do experimento, 0,71 cm. A nodulação (NOD) apresentou diferença significativa entre os tratamentos, destacando-se o tratamento 3 (33\% de VE + 33\% de MC + 33\% de $\mathrm{SM}$ ), com o maior número de nódulos (742 nódulos e média de 29,68 nódulos por planta).

O tratamento com teores iguais de composto orgânico e vermiculita (tratamento 9) apresentou melhores resultados, provavelmente relacionados ao fato de o composto orgânico possuir nutrientes mais prontamente disponíveis à muda e de a vermiculita apresentar melhor

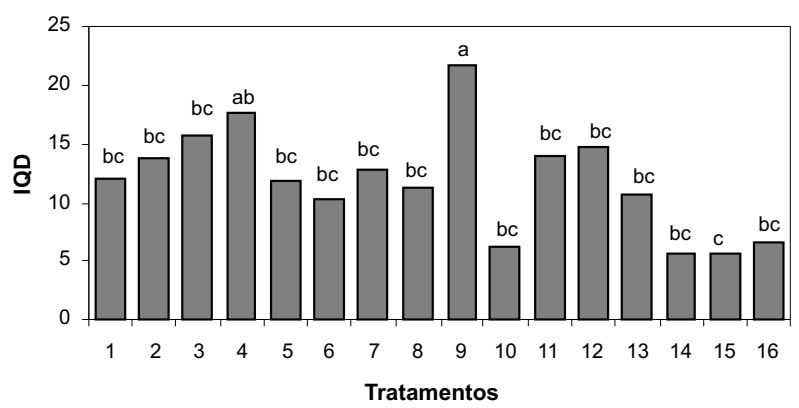

Figura 2 - Avaliação da característica ASC (área sob a curva) para comprimento de raiz. Letras iguais não diferem estatisticamente pelo teste de Tukey a 5\% de significância.

Figure 2-Evaluation of the characteristic (AUC) area under curve of root length. Same letters don't differ statistically according to the test Tukey at level of $5 \%$ significance. estruturação e retenção de umidade. Associado a isso, o mesmo tratamento proporcionou as maiores médias, inclusive com valores superiores aos obtidos nas mudas cultivadas com outros substratos. Esse efeito pode ser também atribuído à condição física do substrato, isto é, características que estimularam o crescimento inicial das plantas. Segundo Bernardino et al. (2005), as produções dessas duas variáveis são consideradas como bons parâmetros para a avaliação da qualidade de mudas.

O efeito significativamente positivo dos substratos enriquecidos com composto orgânico no crescimento das mudas pode estar relacionado com a maior disponibilidade de nutrientes, situado em níveis adequados ao crescimento das plantas. Segundo Cunha et al. (2005), diversos autores têm comprovado que a adição de composto orgânico aos substratos usados para produção de mudas resulta em benefícios como o fornecimento de macro e micronutrientes e a redução do Al trocável. A exemplo de Alves e Passoni (1997), em que mudas de oiti (Licania tomentosa Benth.), produzidas em substrato acrescido de composto orgânico, apresentaram as maiores médias para altura, o que neste estudo não foi diferente.

Todos os substratos apresentaram acidez entre 4,80 e 6,30, o que, de certa forma, foi fator importante a ser determinado, pois, de acordo com Ribeiro et al. (1999), determinadas espécies variam muito na sua capacidade de tolerância ou sensibilidade a acidez ativa, acidez trocável, saturação por bases e saturação por alumínio. Dessa forma, as análises dos substratos (tratamentos) permitem inferir que boa parte deles pode ser utilizada na produção de mudas de $E$. contortisiliquum, devendo, portanto, ser interpretados no sentido de avaliar a disponibilidade e quantidade de nutrientes neles, uma vez que em todos os substratos (tratamentos) houve emergência e sobrevivência das mudas no período do experimento.

A falta ou, mesmo, o excesso de qualquer um dos macronutrientes, dependendo da sua função, pode, segundo Pinto (2003), causar anomalias no crescimento e desenvolvimento da planta, como sintomas de cloroses. Determinados substratos apresentaram elementos com elevados teores de Ca e P, a exemplo dos tratamentos com composto orgânico, em especial os de número 14 e 16 . 
A porcentagem e tempo médio de emergência não apresentaram diferença significativa a 5\% de significância. No entanto, os tratamentos 8 (VE (50\%) + TB (50\%)) e 6 (TB (33\%) + CO (33\%) + SM (33\%)) obtiveram 74,4 e $71,6 \%$, respectivamente, os maiores valores de emergência. Nos demais substratos avaliados, as porcentagens de emergência tiveram valores inferiores e semelhantes entre si, indicando basicamente que as plântulas obtiveram praticamente a mesma porcentagem de emergência no período de 15 dias estudados. Ramos e Andrade (2010) obtiveram emergência de 71,0\% em substrato vermiculita. Entretanto, Scalon et al. (2006) obtiveram 93,09\% de emergência no substrato Plantmax ${ }^{\circledR}$ à base de composto orgânico. Segundo Baldotto et
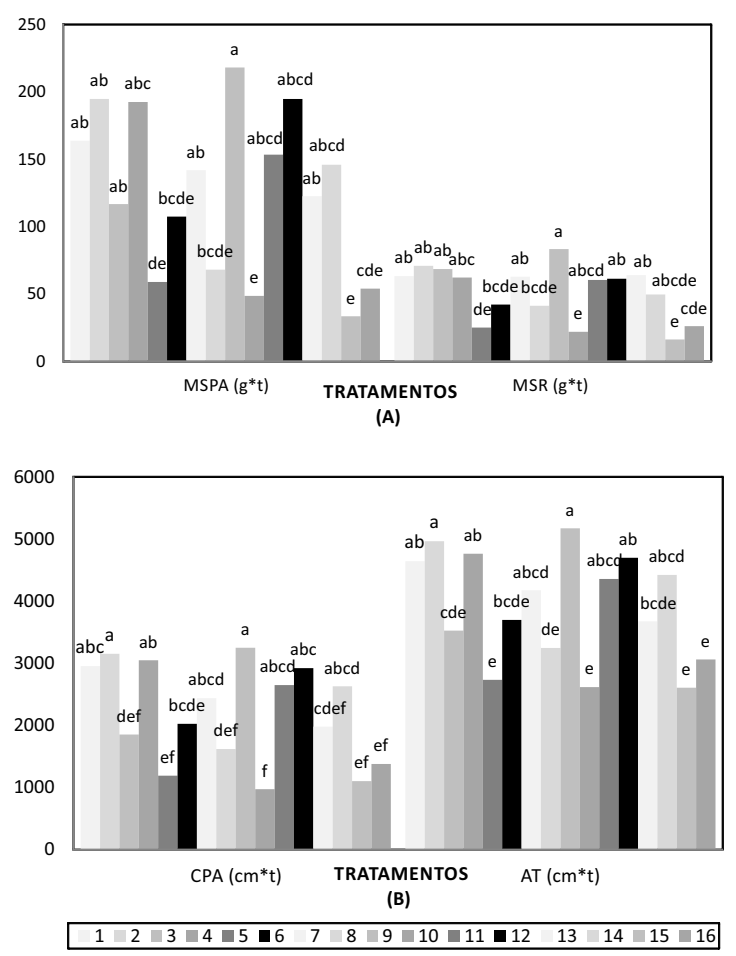

Figura 3 - Avaliação das características em função dos tratamentos: (A) área sob a curva da massa seca da parte aérea $(\mathrm{g} * \mathrm{t})$ e massa seca da raiz $(\mathrm{g} * \mathrm{t})$ e (B) área sob a curva do comprimento da parte aérea CPA $\left(\mathrm{cm}^{*} \mathrm{t}\right)$ e da altura total $(\mathrm{AT} \mathrm{cm} * \mathrm{t})$. Letras iguais não diferem estatisticamente pelo teste de Tukey a 5\% de significância.

Figure 3-Evaluation of the characteristics in function of the treatments: (A) area under curve of the stem dry mass weight and root dry mass and (B) area under curve of the stem length and total height. Same letters do not differ statistically according to the Tukey test (5\% significance). al. (2011), a matéria orgânica, no entanto, é fundamental como fonte de substâncias húmicas fundamentais na emissão e crescimento de raízes. Segundo esses autores, as substâncias húmicas isoladas da matéria orgânica do solo têm sido usadas como estimuladores do metabolismo de plantas e os ácidos húmicos mais estáveis, isolados de solos em estádio de intemperismo menos avançado, com argila de alta atividade e alta saturação por bases, resultaram em melhores estimulantes fisiológicos das plantas de Arabidopsis thaliana L.

Os menores valores de crescimento foram observados nos tratamentos 10 e 15 , o que se deve às baixas concentrações de nutrientes e à baixa capacidade de Capacidade de Troca Catiônica (CTC). O baixo teor de Ca nesse substrato, que tem como consequência um pH mais ácido, provavelmente foi o que causou menor crescimento das mudas nele produzidas, embora apresente maior porcentagem de matéria orgânica. Isso indica que as plântulas de E. contortisiliquum podem ser exigentes em nutrientes nos estágios iniciais de crescimento, sendo necessário semear as sementes em substratos com boa fertilidade.

Os tratamentos 4, 9, 12 e 14 apresentaram baixa nodulação. A ausência de nodulação em uma espécie nodulífera pode estar relacionada a fatores químicos (acidez, deficiência em: P, Mo, Co etc.), físicos (compactação, erosão, salinização etc.) ou biológicos (ausência de estirpes específicas) ou, ainda, segundo Barberi et al. (1998), ao estádio de desenvolvimento da espécie vegetal. Os demais tratamentos não apresentaram grandes limitações.

Verificou-se que, no volume de raízes, houve diferenças significativas de crescimento das mudas, sendo o tratamento 3 com maior volume de raiz, seguido dos tratamentos 9 e 7 . É provável que a quantidade de nódulos contribuiu para essa diferença no volume das raízes.

\section{CONCLUSÃO}

A mistura de 50\% de vermiculita e 50\% de composto orgânico é capaz de promover o crescimento inicial de mudas de orelha-de-macaco, com resultados superiores aos das demais misturas, sendo essa a mais indicada. É ainda a mistura que apresentou mudas de melhor qualidade. As demais misturas podem ser descartadas. 


\section{REFERÊNCIAS}

ABAD, M.; NOGUERA, P.; BURÉS, S. National inventory of organic wastes for use as growing media for ornamental potted plant production: Case study in Spain. Bioresource

Technology, v.77, n.2, p.197-200, 2001.

ABREU, M. F. et al. Reavaliação dos critérios constantes na legislação brasileira para análise de substratos. Bragantina, v.71, n.1, p.106-111, 2012.

AFONSO, M. V. et al. Composição do substrato, vigor e parâmetros fisiológicos de mudas de timbaúva (Enterolobium contortisiliquum (VELL.) MORONG). Revista Árvore, v.36, n.6, p.10191026, 2012.

ALEXANDRE. R. S. et al. Tratamentos físicos e químicos na superação de dormência em sementes de Enterolobium contortisiliquum (Vell.) Morong. Revista Brasileira de Ciências Agrárias, v.4, n.2, p.156-159, 2009.

ALVES, W. L.; PASSONI, A. A. Composto e vermicomposto de lixo urbano na produção de mudas de oiti (Licania tomentosa Benth.) para arborização. Pesquisa Agropecuária Brasileira, v.32, n.10, p.58-62, 1997.

ARAÚJO, A. P.; PAIVA SOBRINHO, S. Germinação e produção de mudas de tamboril (Enterolobium contortisiliquum (Vell.) Morong em diferentes substratos. Revista Árvore, v.35, n.3, p.581588, 2011.

BALDOTTO, M. A. et al. Root growth of Arabidopsis thaliana (L.) Heynh. treated with humic acids isolated from typical soils of Rio de Janeiro State, Brazil. Revista Ceres, v.58, n.4, p.504-511, 2011.

BARBERI, A. et al. Nodulação em leguminosas florestais em viveiros no sul de Minas Gerais. Cerne, v.4, n.1, p.145-153, 1998.

BARRETO, S. S. B.; FERREIRA, R. A. Aspectos morfológicos de frutos, sementes, plântulas e mudas de leguminosae e mimosoideae:

Anadenanthera colubrina (Velloso) Brenan e Enterolobium contortisiliquum (Velloso) Morong. Revista Brasileira de Sementes, v.33, n.2, p.223-232, 2011.
BERNARDINO, D. C. S. et al. Crescimento e qualidade de mudas de Anadenanthera macrocarpa (Benth.) Brenan em resposta à saturação por bases do substrato. Revista Árvore, v.29, n.6, p.863-870, 2005.

BRAGA, L. F.; SOUSA, M. P.; ALMEIDA, T. A. Germinação de sementes de Enterolobium schomburgkii (Benth.) Benth. submetidas a estresse salino e aplicação de poliamina.

Revista Brasileira de Plantas Medicinais, v.11, n.1, p.63-70, 2009.

CAMPBELL, C. L.; MADDEN, L. V. Temporal analysis of epidemics I: Description and comparison of disease progress curves. In: CAMPBELL, C. L.; MADDEN, L. V.

Introduction to plant disease epidemiology. New York: John Wiley, 1990. p.161-202.

CARneiro, J. G. A. Produção e controle de qualidade de mudas florestais. Curitiba: UFPR/FUPEF, Campos: UENF, 1995. 451p.

CUNHA, A. O. et al. Efeitos de substratos e das dimensões dos recipientes na qualidade das mudas de Tabebuia impetiginosa (Mart. ex d.c.). Revista Árvore, v.29, n.4, p.507-516, 2005.

FONSECA, E. P. et al. Padrão de qualidade de mudas de Trema micrantha (L.) Blume, produzidas sob diferentes períodos de sombreamento.

Revista Árvore, v.26, n.4, p.515-523, 2002.

FRANCO, A. A. et al. Revegetação de solos degradados. Seropédica: Emprapa-CNPB, 1992. 11p. (Comunicado técnico, 9)

GOMES, J. M. et al. Parâmetros morfológicos na avaliação da qualidade de mudas de Eucalyptus grandis. Revista Árvore, v.26, n.6, p.655-664, 2002.

GONÇALVES, J. L. M. et al. Produção de mudas de espécies nativas: substrato, nutrição, sombreamento e fertilização. In: GONÇALVES, J. L. M.; BENEDETTI, V. (Ed.) Nutrição e Fertilização Florestal. Piracicaba: IPEF, 2000. p.309-350.

GRANT, C. A. et al. importância do fósforo no desenvolvimento inicial da planta. Piracicaba: Escola Superior de Agricultura Luiz de Queiroz, 2001. (Informações Agronômicas, 95). 
HIGASHIKAWA, F. S.; SILVA, C. A.; BETTIOL, W. Chemical and physical properties of organic residues. Revista Brasileira de Ciências do Solo, v.34, n.5, p.1743-1752, 2010.

IOSSI, E. et al. Efeitos de substratos e temperaturas na germinação de sementes de tamareira - anã (Phoenix roebelenii O’Brien). Revista Brasileira de Sementes, v.25, n.2, p.63-69, 2003.

KÖPPEN, W. Climatologia: com um estúdio de los climas dew la tierra. México: FCE, 1948. p.482-487.

LABORIAU, L. G. A germinação das sementes. Washington: Organização dos Estados Americanos: 1983. 174p.

LIMA, C. M. R. et al. Presence of the cytolytic protein enterolobin in different developmental stages of Enterolobium contortisiliquum seeds. Brazilian Journal of Plant Physiology, v.19, v.2, p.163-170, 2007.

MAGUIRRE, J. D. Speed of germination aid in selection and evaluation for seedling and vigour. Crop Science, v.2, n.2, p.176-177, 1962.

MALAVASI, U. C.; MALAVASI, M. M. Dormancy breaking and germination of Enterolobium contortisiliquum (Vell.) Morong seed. Brazilian Archives of Biology and Technology, v.47, n.6, p.851-854, 2004.
NAKAGAWA, J. Testes de vigor baseados no desempenho das plântulas In: KRZYZANOWSKI, F. C.; VIEIRA, R. D.; FRANÇA NETO, J. B. Vigor de sementes: conceitos e testes. Londrina: Abrates, 1999. p.2.1-2.24.

PINTO, P. Nutrição nas plantas Escola Secundária do Padre António Manuel Oliveira de Lagoa, 2003. n.20. (Apostila).

RAMOS, F. N.; ANDRADE, A. C. S. Seed germination of a rare neotropical canopy tree dormancy and the effects of abiotic factors. Revista Árvore, v.34, n.3, p.443-449, 2010.

RIBEIRO, A. C.; GUIMARÃES, P. T. G.; ALVAREZ V., V. H. Recomendações para o uso de corretivos e fertilizantes em Minas Gerais - $5^{\mathbf{a}}$ Aproximação. Viçosa, MG: Comissão de Fertilidade do Solo do Estado de Minas Gerais, 1999. 359p.

SANTOS, C. B. et al. Efeito do volume de tubetes e tipos de substratos na qualidade de mudas de Cryptomeria japonica (L.F.) D. Don. Ciência Florestal, v.10, n.2, p.1-15, 2000.

SCALON, S. P. Q. et al. Armazenamento, germinação de sementes e crescimento inicial de Enterolobium contortisiliquum (Vell.) Morong. Acta Scientiarum Biological Sciences, v.27, n.2, p.107-112, 2005.

SCALON, S. P. Q. et al. Germinação e crescimento inicial da muda de orelha-de-macaco (Enterolobium contortisiliquum (Vell.) Morong: efeito de tratamentos químicos e luminosidade. Revista Árvore, v.30, n.4, p.529-536, 2006. 
